\title{
KARAKTERISTIK TENAGA KERJA PELAKU MOBILITAS SIRKULER DI KECAMATAN KALAWAT KABUPATEN MINAHASA UTARA
}

\author{
Astrid Salama \\ Theodora M. Katiandagho \\ Benu Olfie L. Suzana
}

\begin{abstract}
This research aims to study the characteristics of circular mobility labor actors in Subdistrict of Kalawat and what the encouraging and binding factors that affect labor circular mobility. The data used in this study are primary data and secondary data. The variables used in this study is the characteristics of respondents, the reason for doing the circular mobility, factors that encourage circular mobility, and the binding factor in the area of origin. Data analysis techniques in this research is descriptive and data presented in table format.The results of this study indicate that there is a dominant factor driving of labor force in the Sub-district of Kalawat to do circular mobility such as: education, transportation, and mileage. While the factors that bind labor circular mobility to remain in the Sub-district of Kalawat is the status of home ownership and living expenses.
\end{abstract}

Keywords: circular mobility, labor, encouraging factors, binding factors, Sub-district of Kalawat, North Minahasa District

\begin{abstract}
ABSTRAK
Penelitian ini bertujuan untuk mempelajari karakteristik tenaga kerja sebagai pelaku mobilitas sirkuler di Kecamatan Kalawat dan apa faktor yang mendorong dan mengikat yang mempengaruhi tenaga kerja melakukan mobilitas sirkuler. Data yang digunakan dalam penelitian ini adalah data primer dan data sekunder. Variabel yang digunakan dalam penelitian ini adalah karakteristik responden, alasan untuk melakukan mobilitas sirkuler, faktor yang mendorong mobilitas sirkuler, dan faktor yang mengikat di daerah asal. Teknik analisis data dalam penelitian ini adalah deskriptif dan data yang disajikan dalam format tabel. Hasil penelitian ini menunjukkan bahwa faktor dominan yang mendorong tenaga kerja di Kecamatan Kalawat untuk melakukan mobilitas sirkuler adalah: pendidikan, transportasi, dan jarak tempuh. faktor- faktor yang mengikat tenaga kerja pelaku mobilitas sirkuler untuk tetap tinggal di Kecamatan Kalawat berupa status kepemilikan rumah dan biaya hidup.
\end{abstract}

Kata kunci: mobilitas sirkuler, tenaga kerja, faktor pendorong, faktor pengikat, Kecamatan Kalawat, Kabupaten Minahasa Utara

\section{PENDAHULUAN}

\section{Latar Belakang}

Otonomi daerah mendorong berbagai daerah untuk membangun dan mengatur rumah tangganya sendiri, melalui sumber- sumber pendapatan yang dimiliki. Indonesia sebagai negara yang memiliki ribuan pulau dengan berbagai karakteristik yang berbeda. Ketidakseragaman ini mempengaruhi proses pembangunan suatu daerah, sehingga terdapat beberapa daerah mampu bertumbuh dengan cepat, sementara daerah lainnya bertumbuh dengan lambat. Perbedaan pertumbuhan daerah ini disebabkan oleh beberapa faktor yaitu; struktur kependudukan, tingkat pendidikan, 
kesehatan, ketenagakerjaan, dan tingkah laku serta etos kerja masyarakat daerah bersangkutan. Perbedaan ini menyebabkan penduduk melakukan perpindahan (mobilitas) dari daerah yang pertumbuhan lambat ke daerah dengan pertumbuhan yang cepat, untuk memperbaiki kualitas hidupnya (Nurman, 2015).

Menurut Rustariyuni (2013) mobilitas penduduk merupakan gerak penduduk yang melintasi batas wilayah dalam periode waktu tertentu. Mobilitas penduduk menjadi semakin tinggi jika di daerah asal terjadi penyempitan lapangan pekerjaan, misalnya menyempitnya lahan pertanian karena alih fungsi lahan. Lahan pertanian diubah menjadi areal pemukiman, pabrik, tempat usaha ataupun akibat hukum waris yang berlaku di daerah tersebut. Semakin tinggi tingkat pendidikan akan menyebabkan masyarakat berusaha mencari kehidupan yang lebih baik, termasuk mencari pekerjaan di daerah yang lainnya. Selain mencari pekerjaan merekapun memilih untuk berpindah ke daerah yang mutu pendidikan lebih baik serta fasilitas lainnya lebih lengkap (Purnomo dalam Ishaq, 2014).

Mobilitas penduduk dapat dibedakan menjadi dua, yaitu: mobilitas permanen (migrasi) dan mobilitas non permanen (sirkuler). Mobilitas permanen adalah perpindahan penduduk melewati batas administrasi suatu daerah dengan tujuan untuk menetap. Mobilitas non- permanen adalah pergerakan penduduk melewati batas administrasi suatu daerah dengan tidak adanya tujuan untuk menetap.

Tabel 1 dapat dilihat bahwa penduduk lebih tertarik melakukan perpindahan dengan tujuan tidak menetap atau melakukan mobilitas sirkuler karena adanya faktor- faktor yang tidak bisa ditinggalkan misalkan faktor keluarga. Tujuan mobilitas sirkuler lebih banyak tertuju ke wilayah perkotaan yang dianggap banyak menyediakan lapangan pekerjaan (Tjiptoherijanto dalam Supriyanto, 2011).

Kabupaten Minahasa Utara terletak di antara Kota Manado dan Bitung sebagai Kawasan Ekonomi Khusus (KEK). Kabupaten
Minahasa Utara merupakan wilayah yang sedang berkembang dalam perekonomian dan pembangunan daerah. Penduduk Minahasa Utara sebagian besar bekerja dan beraktivitas lainnya di luar wilayah Minahasa Utara, seperti data yang tercantum dalam Tabel 1 dimana sebanyak 7,4 persen penduduk melakukan mobilitas Sirkuler. Penduduk Kabupaten Minahasa Utara bermobilitas paling banyak dengan tujuan ke Kota Manado, sebesar 75,78 persen, Kota Bitung (17,11 persen), Kabupaten Minahasa (2,96 persen), Kabupaten Bolaang Mongondow (2,93 persen), Kabupaten Minahasa Selatan (0,88 Persen), dan Kota Tomohon (0,37 persen) (BPS, 2015).

Kecamatan Kalawat merupakan wilayah dengan jumlah penduduk terbanyak di Kabupaten Minahasa Utara, dengan luas wilayah 39.031 ha dengan kepadatan penduduk yang tersebar di 12 desa.

\section{Tabel 1. Presentase Penduduk se Provinsi Sulawesi Utara yang melakukan Mobilitas Sirkuler menurut Kabupaten/ Kota Tahun 2015} Kabupaten/ Kota Mobilitas Sirkuler

\begin{tabular}{cc} 
Bolaang Mongondow & 1,15 \\
Minahasa & 5,44 \\
Kep. Sangihe & 0,00 \\
Kep. Talaud & 0,00 \\
Minahasa Selatan & 0,06 \\
Minahasa Utara & $\mathbf{7 , 4 0}$ \\
Bolaang Mongondow & 0,10 \\
Utara & \\
Sitaro & 0,00 \\
Minahasa Tenggara & 0,14 \\
Bolaang Mongondow & 0,28 \\
Selatan & 1,64 \\
Bolaang Mongondow & \\
Timur & 0,79 \\
Manado & 1,02 \\
Bitung & 4,09 \\
Tomohon & 4,66 \\
Kotamobagu & 2,17 \\
\hline Sulawesi Utara &
\end{tabular}

Sumber: SUPAS BPS Sulut,2015 


\section{Perumusan Masalah}

Bagaimanakah karakteristik tenaga kerja pelaku mobilitas sirkuler di Kecamatan Kalawat Kabupaten Minahasa Utara?

\section{Tujuan}

Tujuan dalam penelitian ini adalah untuk mempelajari karakteristik tenaga kerja pelaku mobilitas sirkuler di Kecamatan Kalawat Kabupaten Minahasa Utara

\section{Manfaat}

Manfaat dari penelitian ini yaitu:

1. Hasil penelitian ini diharapkan mampu memberikan informasi dalam usaha mengetahui karakteristik tenaga kerja mobilitas sirkuler di Kecamatan Kalawat.

2. Sebagai bahan masukan bagi pemerintah atau pihak-pihak terkait dalam pengambilan kebijakan yang berhubungan dengan mobilitas sirkuler Kabupaten Minahasa Utara.

3. Sebagai referensi untuk penelitian selanjutnya tentang karakteristik tenaga kerja pelaku mobilitas sirkuler.

\section{METODE PENELITIAN}

\section{Waktu dan Lokasi Penelitian}

Penelitian ini dilakukan selama 5 (lima) bulan yaitu bulan Desember 2016 sampai bulan April 2017. Penelitian berlokasi di Kecamatan Kalawat Kabupaten Minahasa Utara dengan sampel 3 (tiga) desa yaitu Desa Watutumou, Kawangkoan Baru, Kolongan Tetempangan.

\section{Metode Pengumpulan Data}

Metode pengumpulan data yang digunakan dalam penelitian ini adalah dengan metode survei, wawancara berdasarkan kuesioner dan secara dokumentasi dengan studi pustaka.

\section{Metode Pengambilan Sampel}

Metode pengambilan sampel dilakukan dengan cara sengaja (purposive sampling). Jumlah responden yang diambil sebanyak 30 orang.

\section{Variabel Penelitian}

Variabel dalam penelitian ini adalah Karakteristik responden, alasan melakukan mobilitas sirkuler, faktor yang mendorong melakukan mobilitas, dan faktor pengikat di daerah asal.

\section{Metode Analisis Data}

Data yang di kumpulkan disusun, di analisis secara deskriptif dan data di sajikan dalam bentuk Tabel .

\section{HASIL DAN PEMBAHASAN}

\section{Gambaran Umum Wilayah Penelitian}

Wilayah Kecamatan Kalawat terletak di garis $1,65822^{\circ} \mathrm{LU}-1,80612^{\circ} \mathrm{LU}$ dan $124,96853^{\circ}$ BT- $125,05751^{\circ} \mathrm{BT}$ dan berada di ketinggian \pm 500 meter di atas permukaan laut. Posisi Kecamatan Kalawat sangat strategis karena dekat dengan ibukota Provinsi Sulawesi Utara. Kecamatan Kalawat terdiri atas 12 desa dengan luas 44,21 $\mathrm{Km}^{2}$. Posisi kecamatan Kalawat sangat strategis karena dekat dengan ibukota provinsi dengan batas- batas sebagai berikut:

Sebelah Barat:Kota Manado dan Kabupaten Minahasa. Sebelah Selatan :Kecamatan Aermadidi. Sebelah Timur: Kecamatan Aermadidi. Sebelah Utara: Kecamatan Dimembe dan Kecamatan Talawaan

\section{Jumlah Penduduk}

Jumlah penduduk berdasarkan data yang di ambil kantor Kecamatan Kalawat sebanyak 28,965 jiwa yang terdiri dari lakilaki 14,695 jiwa dan perempuan 14,279 jiwa. Penduduk yang bekerjaberjumlah 16,171 jiwa dan penduduk yang tidak bekerja berjumlah 12,794 jiwa.

\section{Pekerjaan}

Pekerjaan yang utama penduduk di Kecamatan Kalawat terdiri dari sektor formal dan informal yaitu sebagai Petani, PNS, Swasta, Buruh, Tukang Jahit/Bangunan/Besi, dan lain-lain. 


\section{Karakteristik Responden}

\section{Umur}

Berdasarkan Tabel 2 dapat di lihat bahwa tenaga kerja pelaku mobilitas sirkuler yang menjadi responden berumur 19 sampai 32 tahun sebanyak 9 orang atau sebesar 30 persen, 33 sampai 46 tahun sebanyak 11 orang atau 37 persen, dan responden yang berumur 47 sampai 60 tahun sebanyak 10 orang atau sebesar 33 persen. Menunjukkan bahwa tenaga kerja pelaku mobilitas sirkuler di Kecamatan Kalawat memiliki sebaran yang hampir merata di setiap kelompok umur.

\begin{tabular}{|c|c|c|c|}
\hline & $\begin{array}{l}\text { Ke } \\
\text { Sir } \\
\text { Un }\end{array}$ & $\begin{array}{ll}\text { Pelaku } \\
\text { menurut }\end{array}$ & $\begin{array}{l}\text { Mobilitas } \\
\text { Golongan }\end{array}$ \\
\hline No & $\begin{array}{l}\text { Umur } \\
\text { (Tahun) }\end{array}$ & $\begin{array}{c}\text { Responden } \\
\text { (Orang) }\end{array}$ & $\begin{array}{c}\text { Persentase } \\
(\%)\end{array}$ \\
\hline 1 & $19-32$ & 9 & 30 \\
\hline 2 & $33-46$ & 11 & 37 \\
\hline 3 & $47-60$ & 10 & 33 \\
\hline & Total & 30 & 100 \\
\hline
\end{tabular}

Sumber: Diolah dari data primer, 2017

\section{Jenis Kelamin}

Berdasarkan Tabel 3 dapat di lihat tenaga kerja pelaku mobilitas sirkuler yang berjenis kelamin laki-laki sebanyak 18 orang atau dalam persentase sebesar 60 persen dan yang berjenis kelamin perempuan sebanyak 12 orang atau sebesar 40 persen. Tenaga kerja yang berjenis kelamin laki- laki paling banyak berada di kelompok umur sedang dan sudah menikah.

\begin{tabular}{|c|c|c|c|}
\hline & $\begin{array}{l}\text { Kerja } \\
\text { Menur }\end{array}$ & $\begin{array}{l}\text { ku Mobilit } \\
\text { Tenis Kelam }\end{array}$ & Sirkuler \\
\hline No & $\begin{array}{c}\text { Jenis } \\
\text { Kelamin }\end{array}$ & $\begin{array}{c}\text { Responden } \\
\text { (Orang) }\end{array}$ & $\begin{array}{c}\text { Persentase } \\
(\%)\end{array}$ \\
\hline 1 & Laki- laki & 18 & $60 \%$ \\
\hline 2 & Perempuan & 12 & $40 \%$ \\
\hline & Total & 30 & $100 \%$ \\
\hline
\end{tabular}

Sumber: Diolah dari data primer, 2017

\section{Status Pernikahan}

Pada Tabel 4 dapat di lihat bahwa sebagian besar atau sebanyak 25 orang responden sudah menikah, 1 orang pernah menikah dan 4 orang responden belum menikah.

Tabel 4. Jumlah dan Persentase Tenaga Kerja Pelaku Mobilitas Sirkuler Menurut Status Pernikahan

\begin{tabular}{clcc}
\hline No & $\begin{array}{l}\text { Status } \\
\text { Pernikahan }\end{array}$ & $\begin{array}{c}\text { Responden } \\
\text { (Orang) }\end{array}$ & $\begin{array}{c}\text { Persentase } \\
(\%)\end{array}$ \\
\hline 1 & $\begin{array}{l}\text { Sudah } \\
\text { Menikah }\end{array}$ & 25 & 83 \\
2 & $\begin{array}{l}\text { Pernah } \\
\text { Menikah }\end{array}$ & 1 & 3 \\
3 & $\begin{array}{l}\text { Belum } \\
\text { Menikah }\end{array}$ & 4 & 13 \\
\hline & \multicolumn{1}{c}{ Total } & 30 & 100 \\
\hline
\end{tabular}

Sumber: diolah dari data primer, 2017

\section{Pendidikan}

Pendidikan tenaga kerja pelaku mobilitas sirkuler umumnya beragam mulai dari SD sampai Strata 2. Tabel 5 menunjukkan bahwa tingkat pendidikan formal responden tenaga kerja pelaku mobilitas sirkuler yaitu 1 orang atau 3 persen berpendidikan SD, 2 orang atau 7 persen responden yang berpendidikan SMP, 14 orang atau sebesar 47 persen berpendidikan SMA sederajat, 3 orang atau 10 persen responden dan responden yang berpendidikan D2-D3 dan di sebanyak 10 orang atau sebesar 33 persen berpendidikan S1-S2.

\begin{tabular}{clcc} 
Tabel 5. & Jumlah & dan & Persentase \\
Tenaga & Kerja & Pelaku & $\begin{array}{c}\text { Persebilitas } \\
\text { Mirkuler Menurut Pendidikan }\end{array}$ \\
\hline No & $\begin{array}{c}\text { Tingkat } \\
\text { Pendidikan }\end{array}$ & $\begin{array}{c}\text { Responden } \\
\text { (Orang) }\end{array}$ & $\begin{array}{c}\text { Persentase } \\
(\%)\end{array}$ \\
\hline 1 & SD & 1 & 3 \\
2 & SMP & 2 & 7 \\
3 & SMA/SMK & 14 & 47 \\
4 & D2- D3 & 3 & 10 \\
5 & S1- S2 & 10 & 33 \\
\hline \multicolumn{5}{c}{ Total } & 30 & 100 \\
\hline
\end{tabular}

Sumber: diolah dari data primer, 2017

\section{Pendapatan}

Berdasarkan Tabel 6 dapat di lihat bahwa kelompok responden terbesar adalah mereka yang menerima pendapatan antara 2.000.000 sampai 5.600.000 yaitu sebanyak 21 orang atau sebesar 70 persen kemudian yang 
menerima pendapatan sebesar 5.700.000 sampai 9.200.000 sebanyak 7 orang, yang menerima pendapatan sebesar 9.200.000 sampai 20.000.000 sebanyak 2 orang atau sebesar 7 persen. Kelompok responden terbesar memiliki umur yang beragam dan tersebar di semua kelompok umur.

\begin{tabular}{|c|c|c|c|}
\hline & $\begin{array}{l}\text { 6. Jumlah } \\
\text { Kerja I } \\
\text { Menurut }\end{array}$ & $\begin{array}{l}\text { an Persentase } \\
\text { aku Mobilitas } \\
\text { endapatan }\end{array}$ & $\begin{array}{r}\text { Tenaga } \\
\text { Sirkuler }\end{array}$ \\
\hline No & $\begin{array}{c}\text { Jumlah } \\
\text { Pendapatan } \\
\text { (Rp/Bulan) }\end{array}$ & $\begin{array}{l}\text { Responden } \\
\text { (Orang) }\end{array}$ & $\begin{array}{c}\text { Persentase } \\
(\%)\end{array}$ \\
\hline 1 & $\begin{array}{c}2.000 .000 \\
\text { sampai } \\
5.600 .000\end{array}$ & 21 & 70 \\
\hline 2 & $\begin{array}{l}5.700 .000 \\
\text { sampai } \\
9.200 .000\end{array}$ & 7 & 23 \\
\hline \multirow[t]{2}{*}{3} & $\begin{array}{c}9.300 .000 \\
\text { sampai } \\
20.000 .000\end{array}$ & 2 & 7 \\
\hline & Total & 30 & 100 \\
\hline
\end{tabular}

Sumber: diolah dari data primer, 2017

\section{Jumlah Tanggungan Keluarga}

BPS melakukan pengelompokan jumlah tanggungan keluarga dalam beberapa kategori yaitu tanggungan kecil dengan jumlah anggota keluarga 1 sampai 3 orang, sedang dengan jumlah tanggungan keluarga 4 sampai 6 orang dan besar dengan jumlah tanggungan keluarga lebih dari 6 orang. Hasil penelitian yang terangkum Tabel 8 menunjukan bahwa sebagian besar responden tenaga kerja pelaku mobilitas sirkuler yang mempunyai tanggungan 1 sampai 3 orang, yakni sebanyak 22 orang atau sebesar 74 persen dari total responden, serta 4 sampai 6 orang sebanyak 8 orang atau sebesar 26 persen.

\begin{tabular}{cccc} 
Tabel 8. & $\begin{array}{c}\text { Jumlah dan } \\
\text { Kerja Pelaku } \\
\text { Menurut Tanggungan Keluarga }\end{array}$ \\
\hline No & $\begin{array}{c}\text { Jlh } \\
\text { Manggungan }\end{array}$ & $\begin{array}{c}\text { Responden } \\
\text { (orang) }\end{array}$ & Persentase \\
& $\begin{array}{c}\text { Tenaga } \\
\text { Keluarga } \\
\text { (orang) }\end{array}$ & & \\
& $1-3$ & 22 & 74 \\
1 & $4-6$ & 8 & 26 \\
2 & Total & 30 & 100 \\
\hline
\end{tabular}

Sumber: diolah dari data primer, 2017

\section{Faktor- Faktor Pendorong Mobilitas Sirkuler}

Berbagai hasil penelitian menunjukkan bahwa faktor ekonomi merupakan alasan kuat yang menjadi faktor pendorong utama sebagian besar pelaku mobilitas sirkuler untuk bermobilitas. Berbagai jawaban responden yang melakukan mobilitas sirkuler menunjukan bahwa ada beberapa alasan untuk melakukan mobilitas. Gambar 1 menunjukkan alasan responden melakukan mobilitas sirkuler dimana satu orang responden dapat memberikan lebih dari satu alasan.

Gambar 1 dapat di lihat bahwa kebanyakan alasan responden melakukan mobilitas sirkuler karena sudah lama bekerja dan sebelum tinggal di Kecamatan Kalawat mereka sudah bekerja di daerah tujuan, serta merupakan tuntutan pekerjaan yang harus mereka penuhi dan sulit untuk mendapatkan pekerjaan yang sesuai dengan keahlian responden di Minahasa Utara. Alasan ekonomi seperti sulit untuk mendapatkan pekerjaan yang sesuai keahlian dan pendapatan yang lebih basar di daerah tujuan bukanlah faktor utama yang mempengaruhi tenaga kerja melakukan mobilitas.

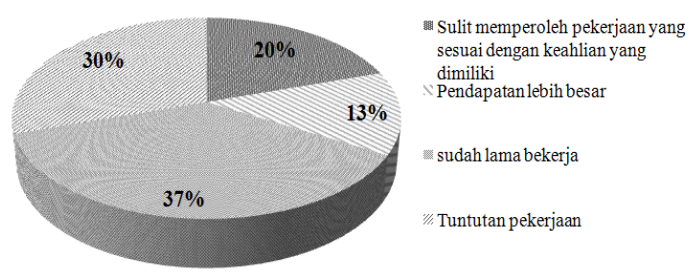

Gambar 1 Alasan Responden melakukan Mobilitas Sirkuler (diolah dari data primer, 2017)

\section{Faktor Pengalaman Bekerja}

Pengalaman bekerja dapat menjadi faktor penyebab seorang tenaga kerja untuk melakukan mobilitas sirkuler. Semakin lama masa kerja seseorang maka semakin banyak pengalaman yang didapat.

Tabel 9 memperlihatkan bahwa responden yang memiliki masa kerja 1 sampai 11 tahun sebanyak 19 orang, 12 sampai 22 tahun sebanyak 6 orang,dan yang memiliki masa kerja 23 sampai 30 tahun sebanyak 5 orang. 
Tebel 9. Jumlah dan Persentase Tenaga Kerja Pelaku Mobilitas Sirkuler Menurut Masa Kerja

\begin{tabular}{cccc}
\hline No & $\begin{array}{c}\text { Masa kerja } \\
\text { (tahun) }\end{array}$ & Responden & Persentase \\
1 & $1-11$ & 19 & 63 \\
2 & $12-22$ & 6 & 20 \\
3 & $23-30$ & 5 & 17 \\
\hline & Total & 30 & 100 \\
\hline
\end{tabular}

Sumber: diolah dari data primer, 2017

\section{Jenis Transportasi}

Faktor transportasi mempunyai peran penting dalam melakukan mobilitas ke suatu daerah karena faktor ekonomi sangat di tentukan oleh transportasi, semakin mudah satu daerah untuk di datangi maka perputaran barang atau jasa semakin mudah untuk di kembangkan. Tersedianya sarana transportasi yang relatif murah menyebabkan banyak tenaga kerja dari satu daerah pergi ke daerah lain.

Pada Tabel 10, hasil pengamatan di lapangan bahwa kebanyakan tenaga kerja pelaku mobilitas sirkuler menggunakan kendaraan pribadi, yang kedua adalah kendaraan umum dan yang ketiga mobil operasional. Jenis kendaraan pribadi yang digunakan paling banyak adalah kendaraan roda dua atau motor.

\begin{tabular}{|c|c|c|c|}
\hline Tal & \multicolumn{3}{|c|}{$\begin{array}{l}\text { 110. Jumlah dan Persentase Tenaga } \\
\text { Kerja Pelaku Mobilitas Sirkuler } \\
\text { Menurut Jenis Transportasi }\end{array}$} \\
\hline No & $\begin{array}{c}\text { Jenis } \\
\text { Transportasi }\end{array}$ & $\begin{array}{c}\text { Responden } \\
\text { (Orang) }\end{array}$ & Persentase \\
\hline 1 & $\begin{array}{c}\text { Kendaraan } \\
\text { Pribadi }\end{array}$ & 22 & 73 \\
\hline 2 & $\begin{array}{c}\text { Kendaraan } \\
\text { Umum }\end{array}$ & 4 & 13 \\
\hline 3 & $\begin{array}{l}\text { Kendaraan } \\
\text { Operasional }\end{array}$ & 3 & 10 \\
\hline 4 & $\begin{array}{c}\text { Dan lain- } \\
\text { lain }\end{array}$ & 1 & 3 \\
\hline & Total & 30 & 100 \\
\hline
\end{tabular}

Sumber: diolah dari data primer, 2017

\section{Jarak}

Faktor jarak merupakan faktor penting dalam penentuan arah, setidak-tidaknya dalam penentuan bentuk mobilitas Penduduk. Kota atau daerah tujuan yang berjarak dekat dengan desa asal cukup di lakukan secara ulang-alik (Commuting).
Tabel 11 menunjukkan bahwa tenaga kerja pelaku mobilitas sirkuler yang memiliki jarak 7.6 sampai 17.1 kilometer sebanyak 19 orang atau sebesar 63 persen, serta 17.2 sampai 26.7 kilometer sebanyak 6 orang atau sebesar 20 persen, dan 26.8 sampai 36.2 kilometer sebanyak 5 orang atau sebesar 17 persen.

\begin{tabular}{|c|c|c|c|}
\hline & \multicolumn{3}{|c|}{$\begin{array}{l}\text { Jumlah dan Persentase Tenaga } \\
\text { Kerja Pelaku Mobilitas Sirkuler } \\
\text { Menurut Jarak Tempuh ke } \\
\text { Tempat Kerja }\end{array}$} \\
\hline No & Jarak (KM) & $\begin{array}{c}\text { Responden } \\
\text { (Orang) }\end{array}$ & $\begin{array}{c}\text { Persentase } \\
(\%)\end{array}$ \\
\hline 1 & $\begin{array}{c}\text { 7.6 sampai } \\
17.1\end{array}$ & 19 & 63 \\
\hline 2 & $\begin{array}{c}17.2 \text { sampai } \\
26.7\end{array}$ & 6 & 20 \\
\hline 3 & $\begin{array}{c}26.8 \text { sampai } \\
36.2\end{array}$ & 5 & 17 \\
\hline & & 30 & 100 \\
\hline
\end{tabular}

Sumber: diolah dari data primer, 2017

\section{Faktor- Faktor Pengikat di Daerah Asal}

Selain ada faktor pendorong yang menyembabkan penduduk melakukan mobilitas sirkuler, maka ada faktor penarik yang menyebabkan penduduk tetap bertahan di daerah asalnya. Dari berbagai jawaban responden yang melakukan mobilitas sirkuler menunjukan bahwa ada beberapa alasan tetap tinggal di daerah asal. Gambar 2 menunjukan alasan responden tetap tinggal di daerah asal dimana satu orang responden dapat memberikan lebih dari satu alasan.

Dari gambar 2 dapat dilihat bahwa 67 persen dari responden memilih tetap tinggal di daerah asal karena terdapat rumah dan keluarga mereka, kemudian sebesar 20 persen memilih tetapi tinggal karena jarak rumah dan tempat kerja cukup dekat selain itu mereka beralasan dekat dengan bandara dan pelabuhan Bitung dan yang lainnya beralasan yaitu akses yang mudah kemana-mana, harga rumah di Kabupaten Minahasa Utara lebih murah, tempat tinggal lebih nyaman di bandingkan di daerah tempat mereka bekerja dan hubungan kekeluargaan yang ada di gereja. 


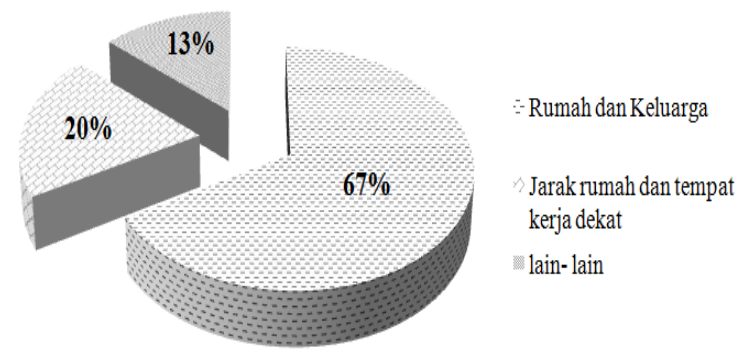

Gambar 6 Alasan Responden Tetap Tinggal di Daerah Asal (diolah dari data primer, 2017)

\section{Kepemilikan Rumah}

Status kepemilikan rumah juga merupakan faktor pengikat tenaga kerja pelaku mobilitas sirkuler untuk tetap tinggal di daerah asal.

Pada Tabel 13 , responden lebih banyak telah memiliki rumah sendiri yaitu sebanyak 22 orang dan 8 orang responden masih tinggal di rumah milik orangtua.

\begin{tabular}{|c|c|c|c|}
\hline & $\begin{array}{l}\text { Jumlah } \\
\text { Kerja Po }\end{array}$ & $\begin{array}{l}\text { lan Pers } \\
\text { laku Mol }\end{array}$ & $\begin{array}{l}\text { tase } \text { Tenaga } \\
\text { itas Sirkuler }\end{array}$ \\
\hline & $\begin{array}{l}\text { Menurut } \\
\text { Rumah }\end{array}$ & Status & Kepemilikan \\
\hline No & $\begin{array}{c}\text { Status } \\
\text { Kepemilikan }\end{array}$ & $\begin{array}{c}\text { Responden } \\
\text { (Orang) }\end{array}$ & $\begin{array}{c}\text { Persentase } \\
(\%)\end{array}$ \\
\hline 1 & Milik Sendiri & 22 & 73 \\
\hline 2 & $\begin{array}{c}\text { Milik } \\
\text { Orangtua }\end{array}$ & 8 & 27 \\
\hline & Total & 30 & 100 \\
\hline
\end{tabular}

Sumber: diolah dari data primer, 2017

\section{Biaya Hidup}

Biaya cukup memiliki pengaruh dalam seseorang bermobilitas, akan jelas kelihatan bahwa biaya memindahkan seseorang secara fisik akan cukup besar. Tingginya biaya hidup di daerah tujuan membuat para pelaku mobilitas tetap tinggal di daerah asal dan tiap hari melakukan mobilitas ke daerah tujuan.

Hasil penelitian menyatakan bahwa biaya hidup yang di keluarkan responden perbulan antara 750.000 sampai 3.500 .000 rupiah sebanyak 16 responden, serta biaya hidup responden perbulan antara 3.600.000 sampai 6.250 .000 rupiah sebanyak 10 responden, dan biaya hidup responden perbulan antara 6.300.000 sampai 9.000 .000 rupiah sebanyak 1 orang.

Tabel 14. Jumlah dan Persentase Tenaga Kerja Pelaku Mobilitas Sirkuler Menurut Biaya Hidup di Daerah Asal

\begin{tabular}{clcc}
\hline No & $\begin{array}{l}\text { Biaya Hidup } \\
\text { (Rp/Bulan) }\end{array}$ & $\begin{array}{c}\text { Responden } \\
\text { (Orang) }\end{array}$ & $\begin{array}{c}\text { Persentase } \\
(\%)\end{array}$ \\
1 & $\begin{array}{l}750.000- \\
\end{array}$ & 16 & 59 \\
2 & $\begin{array}{l}3.500 .000 \\
3.600 .000-\end{array}$ & 10 & 37 \\
& $\begin{array}{l}6.250 .000 \\
3\end{array}$ & & \\
& $\begin{array}{l}6.300 .000- \\
9.000 .000\end{array}$ & 1 & 4 \\
\hline \multicolumn{5}{c}{ Total } & 27 & 100 \\
\hline
\end{tabular}

Sumber: diolah dari data primer, 2017

\section{KESIMPULAN DAN SARAN}

\section{Kesimpulan}

Berdasarkan hasil penelitian menunjukkan bahwa terdapat faktor dominan yang mendorong tenaga kerja di Kecamatan Kalawat melakukan mobilitas sirkuler yaitu pendidikan, transportasi, dan jarak tempuh. Faktor pengikat tenaga kerja untuk tetap tinggal di Kecamatan Kalawat yaitu status kepemilikan rumah dan biaya hidup.

\section{Saran}

Pada studi ini, hal yang di lakukan adalah sebatas menganalisis karakteristik tenaga kerja pelaku mobilitas sirkuler yang ada di Kecamatan Kalawat. Untuk itu di perlukan penelitian lebih lanjut seperti bagaimana dampak ekonomi, sosial maupun budaya bagi daerah asal dan penelitian yang lebih mendalam tentang karakteristik tenaga kerja pelaku mobilitas sirkuler di Minahasa Utara. Pemerintah sebagai pembuat kebijakan harus lebih memperhatikan dalam hal peluang kerja di daerah sehingga akan berkurangnya mobilitas. Hal ini dapat dilakukan dengan membuka peluang investasi bagi para investor atau dengan membebaskan biaya untuk pengusaha yang akan membangun pabrik atau sentra industri didaerah. 


\section{DAFTAR PUSTAKA}

Djojohadikusumo, Sumitro. 1994. Perkembangan pemikiran ekonomi, dasar teori ekonomi pertumbuhan dan ekonomi pembangunan Cet. 1. LP3ES. Jakarta. ISBN 979-8391-26-8.

Handriawan, Budi. 2011. Faktor-Faktor Yang Mempengaruhi Penduduk Melakukan Mobilitas Non Permanen Menjadi Tenaga Kerja Indonesia (Tki) Di Malaysia (Studi Kasus TKI Yang Pulang Di Desa Tanjungsari Kecamatan Jakenan Kabupaten Pati). Skripsi Sarjana: Fakultas Ekonomi. Universitas Negeri Semarang.

Haryono, Tri Joko S. 1999. Jaringan Sosial Migran Sirkuler: Analisis tentang Bentuk dan Fungsi. Jurnal Ilmiah: Jurusan Antropologi FISIP, Universitas Airlangga.
Mantra, Ida Bagoes. 2015. Demografi Umum. Pustaka Pelajar. Yogyakarta. ISBN 9799289-61-0.

Nurman. 2015. Strategi Pembangunan Daerah. -Ed 1. -Cet. 1. PT. RajaGrafindo Persada. Jakarta. ISBN 978-979-769-861-4.

Purnomo, Didit. 2004. Studi Tentang Pola Migrasi Migran Sirkuler Asal Wonogiri ke Jakarta. Thesis: Program Pascasarjana. Universitas Diponegoro. Semarang.

Santoso, Rokhedi Priyo. 2012. Ekonomi Sumber Daya Manusia dan Ketenagakerjaan. UPP STIM YKPN. Yogyakarta. 